OPEN ACCESS

Edited by:

Miguel Angel Prieto Lage, University of Vigo, Spain

Reviewed by:

Zhiyuan Fang

Guangdong University of

Technology, China

Franklin Chamorro,

University of Vigo, Spain

Antía González Pereira,

University of Vigo, Spain

${ }^{*}$ Correspondence:

Ge Chen

chenge@caas.cn

Donghui Xu

xudonghui@caas.cn

Specialty section:

This article was submitted to

Food Chemistry,

a section of the journal

Frontiers in Nutrition

Received: 22 November 2021

Accepted: 03 January 2022

Published: 07 February 2022

Citation:

Chen G, Zhai R, Liu G, Huang X, Zhang $K, X u X, L i L$, Zhang Y, Wang J, Jin M, Xu D and Abd El-Aty AM (2022) A Competitive Assay Based on

Dual-Mode Au@Pt-DNA Biosensors for On-Site Sensitive Determination of Carbendazim Fungicide in Agricultural

Products. Front. Nutr. 9:820150

doi: 10.3389/fnut.2022.820150

\section{A Competitive Assay Based on Dual-Mode Au@Pt-DNA Biosensors for On-Site Sensitive Determination of Carbendazim Fungicide in Agricultural Products}

\author{
Ge Chen ${ }^{1 *}$, Rongqi Zhai ${ }^{1}$, Guangyang Liu ${ }^{1}$, Xiaodong Huang ${ }^{1}$, Kaige Zhang ${ }^{1}$, \\ Xiaomin $\mathrm{Xu}^{1}$, Lingyun $\mathrm{Li}^{1}$, Yanguo Zhang ${ }^{1}$, Jing Wang ${ }^{2}$, Maojun $\mathrm{Jin}^{2}$, Donghui $\mathrm{Xu}^{1 *}$ and \\ A. M. Abd El-Aty ${ }^{3,4,5}$
}

${ }^{1}$ Key Laboratory of Vegetables Quality and Safety Control, Laboratory of Quality and Safety Risk Assessment for Vegetable Products, Ministry of Agriculture and Rural Affairs, Institute of Vegetables and Flowers, Chinese Academy of Agricultural Sciences, Beijing, China, ${ }^{2}$ Key Laboratory of Agro-Product Quality and Safety, Ministry of Agriculture and Rural Affairs, Institute of Quality Standard and Testing Technology for Agro-Products, Chinese Academy of Agricultural Sciences, Beijing, China, ${ }^{3}$ State Key Laboratory of Biobased Material and Green Papermaking, College of Food Science and Engineering, Qilu University of Technology, Shandong Academy of Science, Jinan, China, ${ }^{4}$ Department of Pharmacology, Faculty of Veterinary Medicine, Cairo University, Giza, Egypt, ${ }^{5}$ Department of Medical Pharmacology, Faculty of Medicine, Atatürk University, Erzurum, Turkey

Carbendazim (CBZ), a systemic, broad-spectrum benzimidazole fungicide, is widely used to control fungal diseases in agricultural products. Its residues might pose risks to human health and the environment. Therefore, it is warranted to establish a rapid and reliable method for its residual quantification. Herein, we proposed a competitive assay that combined aptamer (DNA) specific recognition and bimetallic nanozyme gold@platinum (Au@Pt) catalysis to trace the CBZ residue. The DNA was labeled onto bimetallic nanozyme Au@Pt surface to produce Au@Pt probes (Au@Pt-DNA). The magnetic $\mathrm{Fe}_{3} \mathrm{O}_{4}$ was functionalized with a complementary strand of DNA (C-DNA) to form $\mathrm{Fe}_{3} \mathrm{O}_{4}$ probes ( $\mathrm{Fe}_{3} \mathrm{O}_{4}-\mathrm{C}$-DNA). Subsequently, the $\mathrm{CBZ}$ and the $\mathrm{Fe}_{3} \mathrm{O}_{4}$ probes competitively react with Au@Pt probes to form two Au@Pt-DNA biosensors (Au@Pt-ssDNA-CBZ and $\mathrm{Au} @ \mathrm{Pt}-\mathrm{dsDNA}-\mathrm{Fe}_{3} \mathrm{O}_{4}$ ). The Au@Pt-ssDNA-CBZ biosensor was designed for qualitative analysis through a naked-eye visualization strategy in the presence of CBZ. Meanwhile, $\mathrm{Au} @ P t-d s D N A-\mathrm{Fe}_{3} \mathrm{O}_{4}$ biosensor was developed to quantitatively analyze CBZ using a multifunctional microplate reader. A competitive assay based on the dual-mode Au@Pt-DNA biosensors was established for onsite sensitive determination of CBZ. The limit of detection (LOD) and recoveries of the developed assay were $0.038 \mathrm{ng} / \mathrm{mg}$ and $71.88-110.11 \%$, with relative standard deviations (RSDs) ranging between 3.15 and $10.91 \%$. The assay demonstrated a good correlation with data acquired from liquid chromatography coupled with mass spectrometry/mass spectrometry analysis. In summary, the proposed competitive assay based on dual-mode Au@Pt-DNA biosensors might have a great potential for onsite sensitive detection of pesticides in agro-products.

Keywords: carbendazim, Au@Pt-DNA, pesticide residue, biosensor, aptamer 


\section{INTRODUCTION}

Carbendazim (CBZ) is a broad-spectrum benzimidazole fungicide used to protect a wide variety of crops against fungal disease, thus producing high-quality crops with optimal yields $(1,2)$. CBZ, which interferes with DNA biosynthesis during fungal cell division, was defined as a major agrochemical pollutant, hazardous to humans and the environment. Because of its long half-life and severe toxicity, residues might threaten safe consumption and negatively influence food quality (3). There is an urgent need to develop analytical methods to determine residual trace levels of $\mathrm{CBZ}$ in agro-products to protect public health. To date, a variety of classical quantitive analyses, including liquid chromatography coupled with mass spectrometry (LC-MS) (4) and gas chromatography coupled with tandem mass spectrometry (GC-MS/MS) (5), have been routinely used to monitor $\mathrm{CBZ}$ residues in the agricultural products. Although these analytical methods provide high stability and accuracy, preparation steps are laborious, timeconsuming, requiring professional operators and expensive instruments (2), restricting their applications. Therefore, a sensitive, rapid, and simple analytical method is needed to detect CBZ. Currently, the rapid immunoassay for detecting CBZ with high sensitivity and specificity (6) overcomes the pitfalls of the traditional analytical methods (7). However, the antibodies are prone to degradation and denaturation during field applications (8), resulting in difficultly in specifically recognizing the target (9). Moreover, antibodies are more complicated, and the manufacturing process is costly and time consuming (10). Furthermore, haptens synthesized from the CBZ analogs can attach to the appropriate functional groups, enabling the conjugation with the protein (11). Hence, a stable, specific, and cost-effective recognition receptor for $\mathrm{CBZ}$ is strongly required to replace the traditional immunoassays.

As molecular recognition elements, aptamers are artificially synthesized single-stranded nucleotide sequences, screened through systematic evolution of ligands by exponential enrichment (SELEX) techniques, and could specifically bind the target analyte (12). Aptamers have attracted significant attention because of their advantages of easy synthesis, low cost, and high affinity (13). Unlike antibodies, aptamers are relatively stable under extreme temperature conditions for a short time (14). Therefore, several platforms of aptamer sensors, such as fluorescence (15), colorimetry (16), and electrochemistry (17), have been developed for the detection of pesticides. To improve the stability and sensitivity of aptamer-based assays, nanomaterials (one of the most interesting sensing materials) are bioconjugated with aptamers for selective and sensitive detection of analytes. The nanomaterials with some enzyme-mimicking characteristics are defined as nanozymes (18). Nanozyme, an emerging alternative to the natural enzyme (19), displayed the following advantages: simple preparation methods, high stability, easy surface modification, and low cost (20). Some enzyme-like bimetallic nanomaterials Au@Pt are of great interest because of their multifunctional and synergistic properties (21). Au@Pt combines good chemical stability of Au with specific catalytic activities of Pt (22). Moreover, the DNA could be firmly bound to the surface of Au@Pt (23). Meanwhile, the recent reports have demonstrated that Au@Pt exhibited high-catalytic properties $(24,25)$.

Herein, a competitive assay based on dual-mode Au@Pt-DNA biosensors for onsite sensitive determination of $\mathrm{CBZ}$ fungicide is shown in Figure 1. One promising strategy is to reversibly bind target-specific aptamers (DNA) to the Au@Pt surface. The magnetic $\mathrm{Fe}_{3} \mathrm{O}_{4}$ was functionalized with a complementary strand of DNA (cDNA) to form $\mathrm{Fe}_{3} \mathrm{O}_{4}$ probes $\left(\mathrm{Fe}_{3} \mathrm{O}_{4}-\mathrm{C}\right.$ DNA). The $\mathrm{CBZ}$ and the $\mathrm{Fe}_{3} \mathrm{O}_{4}$ probes competitively react with DNA-modified nanozyme Au@Pt to form two Au@PtDNA biosensors (Au@Pt-ssDNA-CBZ and Au@Pt-dsDNA$\mathrm{Fe}_{3} \mathrm{O}_{4}$ biosensors, respectively). The aptamers only extend from the Au@Pt surface, specifically in the presence of the CBZ (26), which forms Au@Pt-ssDNA-CBZ biosensor for the qualitative analysis through visualization by naked-eye from light blue to dark blue (19). In addition, $\mathrm{Au} @ \mathrm{Pt}-\mathrm{dsDNA}-\mathrm{Fe}_{3} \mathrm{O}_{4}$ biosensor was established for quantitative analysis of CBZ by constructing a calibration curve for trace residual determination of $\mathrm{CBZ}$ in agricultural products.

\section{MATERIALS AND METHODS}

\section{Materials and Reagents}

Gold $(\mathrm{Au})$ chloride hydrate $\left(\mathrm{HAuCl}_{4} \bullet \mathrm{xH}_{2} \mathrm{O}\right)$, chloroplatinic acid $\left(\mathrm{H}_{2} \mathrm{PtCl}_{6} \bullet 6 \mathrm{H}_{2} \mathrm{O}\right)$, sodium citrate $\left(\mathrm{C}_{6} \mathrm{H}_{5} \mathrm{Na}_{3} \mathrm{O}_{7} \bullet 2 \mathrm{H}_{2} \mathrm{O}\right.$, purity $>99 \%), \mathrm{Fe}_{3} \mathrm{O}_{4}(10 \mathrm{mg} / \mathrm{ml})$, 1-ethyl-3-[3-(dimethylamino) propyl] carbodiimide (EDC), and N-hydroxysuccinimide (NHS) were acquired from Sigma-Aldrich (St. Louis, MO, USA). L-ascorbic acid $\left(\mathrm{C}_{6} \mathrm{H}_{8} \mathrm{O}_{6}\right.$, LAA) was procured from Macklin Biochemical Co., Ltd (Shanghai, China). Carboxylfunctionalized magnetic particles $\left(\mathrm{Fe}_{3} \mathrm{O}_{4}, 10 \mathrm{mg} / \mathrm{ml}\right)$ were secured from Invitrogen (Grand Island, NY). CBZ standard $\left(\mathrm{C}_{9} \mathrm{H}_{9} \mathrm{~N}_{3} \mathrm{O}_{2}\right.$, purity $\left.>99 \%\right)$ was obtained from Dr. Ehrenstorfer $\mathrm{GmbH}$ (Augsburg, Germany). Polyethylene glycol 20,000 (PEG 20,000), Tween-20, Tris-EDTA buffer (TE, pH 8.0), and 3,3'5,5'-tetramethylbenzidine (TMB) substrate were purchased from Solarbio (Beijing, China). Primary secondary amine (PSA) and octadecyl (C18) were picked up from Shimadzu (Kyoto, Japan). Anhydrous magnesium sulfate $\left(\mathrm{MgSO}_{4}\right)$, sodium chloride $(\mathrm{NaCl})$, potassium chloride $(\mathrm{KCl})$, disodium phosphate $\left(\mathrm{Na}_{2} \mathrm{HPO}_{4}\right)$, potassium dihydrogen phosphate $\left(\mathrm{KH}_{2} \mathrm{PO}_{4}\right)$, and other analytical grade reagents were supplied by Sinopharm Chemical Reagent Co., Ltd. (Beijing, China). Hydrochloric acid $(\mathrm{HCl})$ and nitric acid $\left(\mathrm{HNO}_{3}\right)$ were provided by Beijing Chemical Industry Group Co., Ltd. (Beijing, China). The CBZ aptamer (DNA) and C-DNA (the sequence of DNA and C-DNA designed in Supplementary Table 1) were synthesized by Sangon Co., Ltd. (Shanghai, China). A 96-well micro-plate (Transplant, flat bottom) was supplied by Costar, Inc. (Kennebunk, ME, USA). The HPLC-grade acetonitrile (ACN) and methanol $(\mathrm{MeOH})$ were obtained from Thermo Fisher Scientific (Pittsburgh, PA, USA). Ultrapure water was purified by a Milli-QRC purification system (Millipore, Bedford, MA, USA). Aqua regia is a mixture of $\mathrm{HCl}$ and $\mathrm{HNO}_{3}\left(\mathrm{HCl} / \mathrm{HNO}_{3}=3 / 1\right)$. The $0.01 \mathrm{M}$ phosphatebuffered saline (PBS buffer, $\mathrm{pH} 7.4$ ) consists of $0.2 \mathrm{~g} \mathrm{KCl}, 0.27 \mathrm{~g}$ $\mathrm{KH}_{2} \mathrm{PO}_{4}, 8 \mathrm{~g} \mathrm{NaCl}$, and $1.14 \mathrm{~g} \mathrm{Na} \mathrm{HPO}_{4}$. Washing buffer (PBST: 


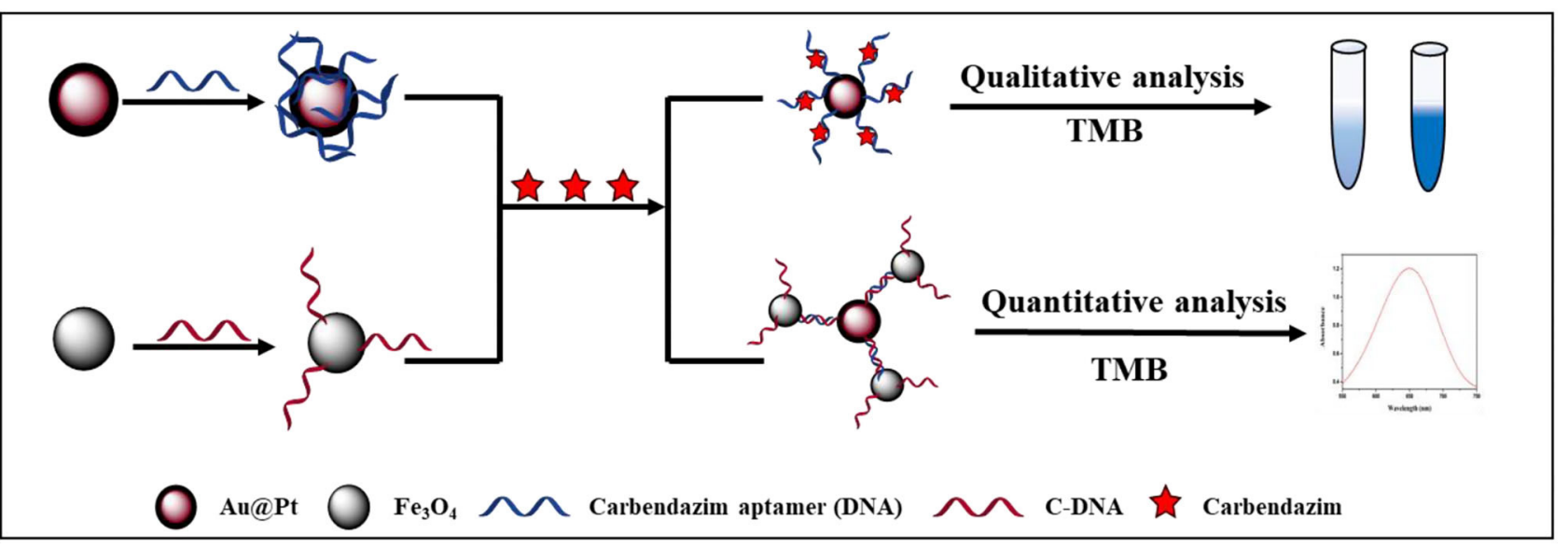

FIGURE 1 | Schematic illustration of a competitive assay based on dual-mode Au@Pt-DNA biosensors for the sensitive determination of CBZ fungicide.

PBS buffer containing $0.05 \%$ Tween-20) was prepared for washing micro-plates.

\section{Preparation of Au@Pt Nanomaterials}

The Au@Pt nanomaterials were prepared by the seed-mediated growth method (27). All the glassware was thoroughly soaked in aqua regia and rinsed with ultrapure water. At first, the seeds of gold nanoparticles (AuNPs) were prepared with mirror modifications (28). AuNPs were synthesized by a chemical reduction method where $\mathrm{HAuCl}_{4}$ was used as a precursor, and trisodium citrate was used as a reducing agent and stabilizing agent $(29,30)$. One milliliter $\mathrm{HAuCl}_{4}(10 \%, w / v)$ aqueous solution and $99 \mathrm{ml}$ distilled water were added to a roundbottomed flask. After that, $10 \mathrm{ml}$ of trisodium citrate $(38.8 \mathrm{mM})$ solution was quickly added when the aforementioned mixture heated to boiling under vigorous stirring and refluxing using a magnetic stirring heater (Zhengzhou, China). The color of the solution was changed from yellow to wine red, and the mixture was left to stir for another $20 \mathrm{~min}$.

Second, Au@Pt was synthesized using AuNPs (30 ml) as seeds as follows: $\mathrm{H}_{2} \mathrm{PtCl}_{6}(1.0 \mathrm{mM}, 10 \mathrm{ml})$ solution and LAA $(5 \mathrm{mM}$, $10 \mathrm{ml}$ ) were added to the AuNPs solution and heated to boiling until the color changes from wind red to brown-red. Then, the aforementioned aqueous solution was left to stir for another $30 \mathrm{~min}$ to ensure a comprehensive reduction of $\mathrm{H}_{2} \mathrm{PtCl}_{6}$. The synthetic Au@Pt was cooled to room temperature, stored in the dark at $4^{\circ} \mathrm{C}$, and then filtered through a cellulose nitrate filter.

\section{Construction of Au@Pt Probe}

Sangon Biotech Co., Ltd. synthesized the aptamer (DNA) of CBZ. The aptamer (DNA) sequence of CBZ was acquired from literature (31). Before using the aptamer (DNA) of CBZ (35.08 $\mu \mathrm{g})$, it should be activated. At first, $18 \mu \mathrm{l}$ TE buffer was added into the microcentrifuge tube with the aptamer (DNA) of CBZ to dissolve, and $18 \mu \mathrm{l}$ TCEP solution was then added to reduce the disulphide bonds to single sulfhydryl groups. Subsequently, the DNA solution was shaken for $3 \mathrm{~h}$ under $200 \mathrm{rpm}$. After that, the activated DNA reacts with Au@Pt solution to form an
Au@Pt probe (Au@Pt-DNA). The 30\% PEG and 0.1 M PBS were selected to stabilize the Au@Pt probe to achieve 0.5\% PEG and $0.01 \mathrm{M}$ PBS in the final solution and avoid the aggregation of the Au@Pt probe (Au@Pt-DNA).Afterward, unbound aptamer of CBZ (DNA) was removed by centrifugation at 10,000 rpm for $30 \mathrm{~min}$. The Au@Pt probe was kept refrigerated at $4^{\circ} \mathrm{C}$ for further analysis.

\section{Construction of $\mathrm{Fe}_{3} \mathrm{O}_{4}$ Probe}

At first, the C-DNA (33.26 $\mu \mathrm{g})$ should be activated before conjugation with $\mathrm{Fe}_{3} \mathrm{O}_{4}$. The TE buffer ( $\mathrm{pH} 8.5,18 \mu \mathrm{l}$ ) was added to the C-DNA. Next, the NHS $(10 \mathrm{mg} / \mathrm{ml}, 100 \mu \mathrm{l})$ and EDC $(10 \mathrm{mg} / \mathrm{ml}, 100 \mu \mathrm{l})$ were selected to activate the carboxyl group of $\mathrm{Fe}_{3} \mathrm{O}_{4}(10 \mu \mathrm{l}, 10 \mathrm{mg} / \mathrm{ml})$ with gentle shaking for $30 \mathrm{~min}$. The $\mathrm{Fe}_{3} \mathrm{O}_{4}$ was magnetically separated and washed three times with MES buffer $(15 \mathrm{mM})$ for $1 \mathrm{~min}$. The washed $\mathrm{Fe}_{3} \mathrm{O}_{4}$ was resuspended in PBS buffer ( $\mathrm{pH} 7.4,0.1 \mathrm{~mol} / \mathrm{L}$ ). After that, the activated C-DNA was added to $\mathrm{Fe}_{3} \mathrm{O}_{4}$ solution to construct $\mathrm{Fe}_{3} \mathrm{O}_{4}$ probe $\left(\mathrm{Fe}_{3} \mathrm{O}_{4}\right.$-C-DNA) for $18 \mathrm{~h}$ at $4^{\circ} \mathrm{C}$. The $\mathrm{Fe}_{3} \mathrm{O}_{4}$ probe was washed three times with PBS buffer to remove the unconjugated C-DNA. Finally, the $\mathrm{Fe}_{3} \mathrm{O}_{4}$ probe was resuspended in $500 \mu \mathrm{lBBS}(\mathrm{pH} 7.4,0.1 \mathrm{~mol} / \mathrm{L})$ and stored at $4^{\circ} \mathrm{C}$ for further use.

\section{A Competitive Assay Based on $\mathrm{Au} @ P t-D s D N A-\mathrm{Fe}_{3} \mathrm{O}_{4}$ Biosensor}

In general, the quantitative analysis of CBZ was carried out as follows: at first, $150 \mu \mathrm{l}$ Au@Pt-DNA (0.3 nmol/L) was added to a $0.5-\mathrm{ml}$ microcentrifuge tube. Then, different concentrations of CBZ standard were prepared by PBS solution containing 10\% methanol or supernatant of actual samples extract in advance. Afterward, $60 \mu \mathrm{l}$ CBZ was added to Au@Pt-DNA solution, followed by adding a $60 \mu \mathrm{l} \mathrm{Fe}_{3} \mathrm{O}_{4}$ probe (diluted by probe buffer, $0.1 \mathrm{mg} / \mathrm{L}$ ) to construct a competitive assay at room temperature. The aforementioned mixture was washed three times, followed by separation under a magnetic field for $1 \mathrm{~min}$. After that, the Au@Pt-dsDNA- $\mathrm{Fe}_{3} \mathrm{O}_{4}$ mixture was resuspended 


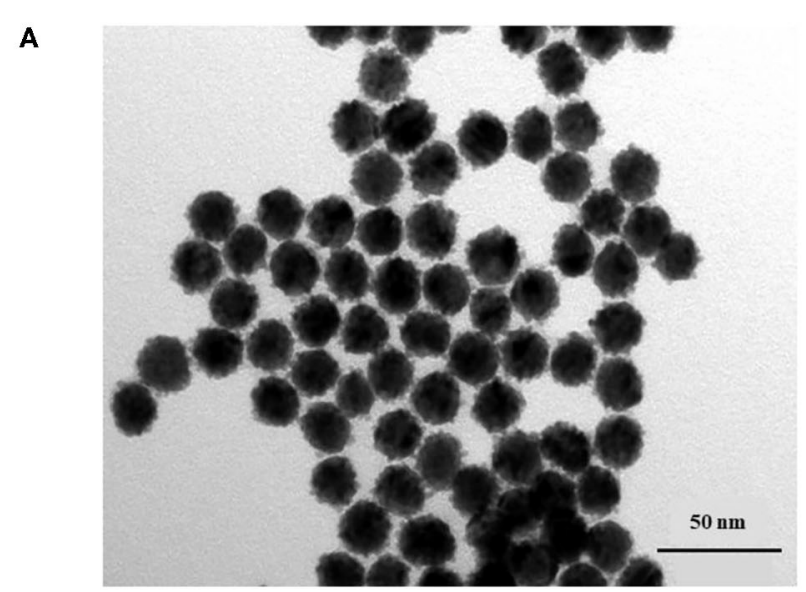

C

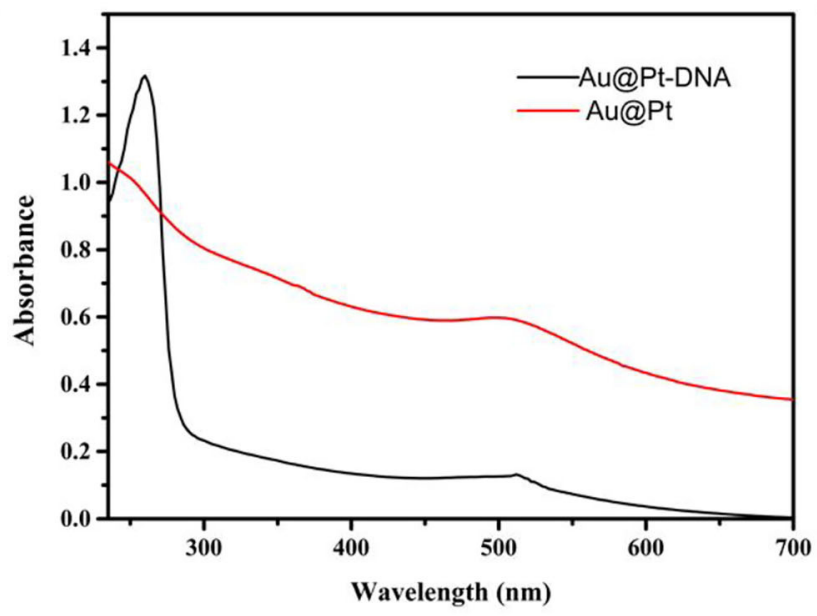

B

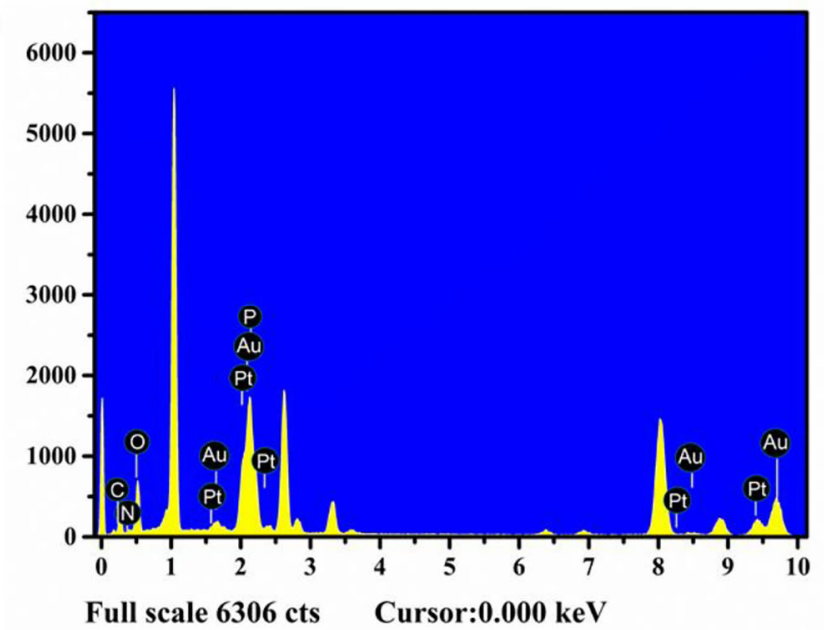

$\mathbf{D}$

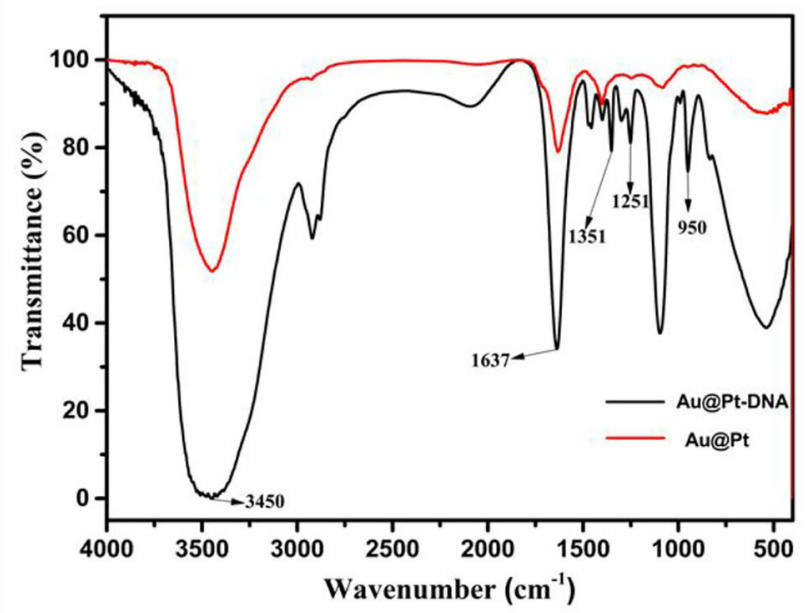

FIGURE 2 | Characterization of Au@Pt and Au@Pt probes. (A) TEM of Au@Pt; (B) EDS of Au@Pt probe; (C) UV-Vis spectra of Au@Pt and Au@Pt probes; and (D) FTIR spectra of Au@Pt and Au@Pt probes.

in PBS buffer to catalyze TMB for the trace detection of CBZ using a multifunctional microplate reader (Salzburg, Austria).

\section{Sample Preparation}

The leeks and rice samples were obtained from the Shangdong vegetable production field to evaluate the feasibility of the developed assay. Blank samples (free from CBZ) were used for creating a calibration curve and recovery experiments. The leeks and rice samples were pretreated with QuEChERS (quick, easy, cheap, effective, rugged, and safe) method designed by the Anastassiades team (32) with slight modifications. Standard concentrations $\left(10,50\right.$, and $\left.100 \mu \mathrm{g} \cdot \mathrm{kg}^{-1}\right)$ were used as spiking levels to homogenized samples ( $10 \mathrm{~g}$ for leeks, $5 \mathrm{~g}$ for rice) in 50 $\mathrm{ml}$ centrifuge tubes. Afterward, the spiked samples were allowed to equilibrate at room temperature for $4 \mathrm{~h}$. Subsequently, $10 \mathrm{ml}$ acetonitrile was added, followed by a 2 min vortex mix. Next, $2 \mathrm{~g}$ anhydrous $\mathrm{MgSO}_{4}$ and $1 \mathrm{~g} \mathrm{NaCl}$ were added for dehydration and stratification (vigorous shaking for $1 \mathrm{~min}$ ). The supernatant was transferred into a $10-\mathrm{ml}$ plastic tube, vortexed for another $1 \mathrm{~min}$, and centrifuged at $5,000 \mathrm{rpm}\left(\right.$ at $4^{\circ} \mathrm{C}$ ) for $5 \mathrm{~min}$. Subsequently, $5 \mathrm{ml}$ supernatant was purified using a purification cartridge (52 mg PSA, $52 \mathrm{mg} \mathrm{C18}$, and $26 \mathrm{mg}$ GCB), vortexed again for $1 \mathrm{~min}$, and then centrifuged at $10,000 \mathrm{rpm}$ (at $4^{\circ} \mathrm{C}$ ) for $5 \mathrm{~min}$. Finally, the supernatant was filtered through a $0.22-\mu \mathrm{m}$ filter (Jinteng, China) for competitive assay based on Au@Pt-dsDNA$\mathrm{Fe}_{3} \mathrm{O}_{4}$ biosensor and LC-MS/MS analysis.

\section{RESULTS}

\section{Characterization of Au@Pt and Au@Pt Probe}

Using $\mathrm{Au}$ as seeds, a thin Pt layer was deposited on the surface of the Au core to achieve Au@Pt. The morphology of Au@Pt nanoparticles was characterized by transmission electron microscopy (TEM). As shown in Figure 2A, the Au@Pt showed uniform spherical shapes with an average 


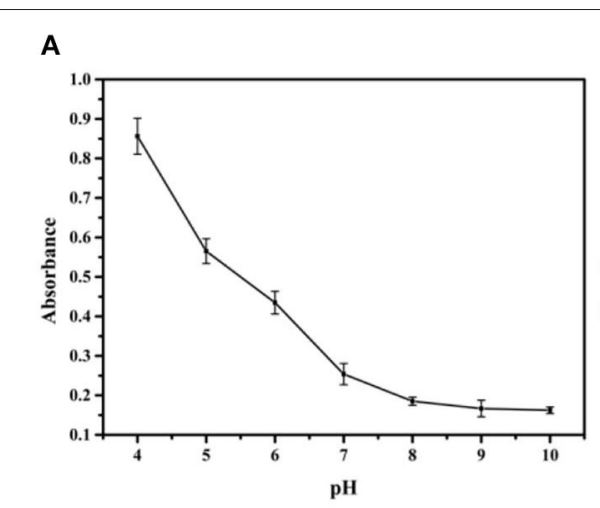

B

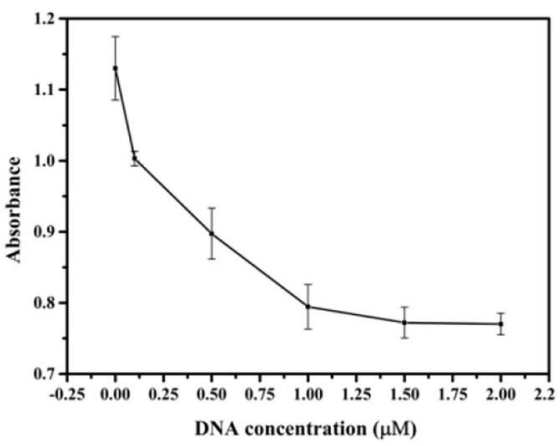

C

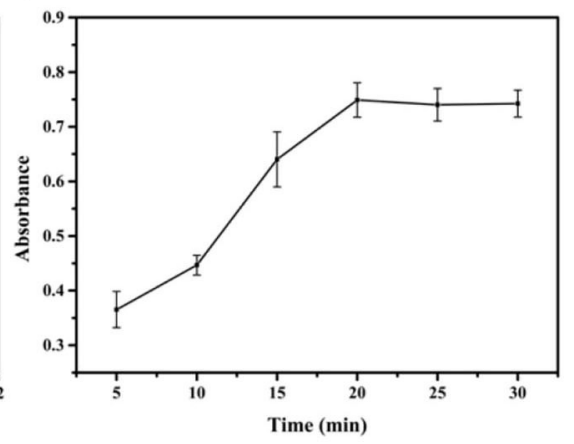

FIGURE 3 | Optimization of the experimental conditions. (A) pH; (B) DNA concentration; and (C) reaction time.

particle size of $20 \mathrm{~nm}$. Compared with smooth $\mathrm{Au}$ (as shown in Supplementary Figure 1A). The particle size of $\mathrm{Au} @ \mathrm{Pt}$ was increased by $\sim 5 \mathrm{~nm}$ indicating the existence of smooth AuNPs surface of a $5 \mathrm{~nm}$ layer Pt. The TEM images of $\mathrm{Au} @ \mathrm{Pt}$ demonstrated that the Au@Pt core-shell structure was successfully prepared. Then, the Au@Pt and Au@Pt probes were carefully characterized by energy dispersive spectrometer (EDS). As presented in Figure 2B, the EDS of Au@Pt probe has shown that $P$ element signal except for $\mathrm{Au}$ and $\mathrm{Pt}$, which are from $\mathrm{Au} @ \mathrm{Pt}$ nanoparticles (as depicted in Supplementary Figure 1B). Therefore, the $P$ characteristic element can be inferred from the DNA. The EDS (Hitachi Co., Ltd., Tokyo, Japan) of Au@Pt and Au@Pt probes indicate that the DNA was successfully modified on the Au@Pt surface. To further confirm the successful preparation of the Au@Pt probe, the UV-vis spectra (Shimadzu, Japan) were used to verify the synthesized Au@Pt probe. The UV-vis spectra of Au@Pt (red line) have a maximum absorbance at $508 \mathrm{~nm}$. Compared with Au@Pt, a prominent characteristic absorbance peak near $260 \mathrm{~nm}$ was noticed in UVvis spectroscopy of Au@Pt probe (black line), as presented in Figure 2C. As reported, the maximum absorption peak of DNA occurs at $260 \mathrm{~nm}$ (23), denoting that the Au@Pt surface was conjugated with DNA. In addition, the Au@Pt probe was characterized by FT-IR (Pittsburgh, USA), as depicted in Figure 2D. Peaks around 3,450 and $1,637 \mathrm{~cm}^{-1}$ are derived from the $\mathrm{O}-\mathrm{H}$ stretching, representing the $\mathrm{H}-\mathrm{O}-\mathrm{H}$ bending vibration of water. The characteristic peaks of $1,351,1,251$, and $950 \mathrm{~cm}^{-1}$ were observed except for 3,450 and $1,637 \mathrm{~cm}^{-1}$ in the Fouriertransform infrared spectroscopy (FTIR) spectra of the Au@Pt probe. These characteristic peaks, corresponding to $\mathrm{C}=\mathrm{C}, \mathrm{C}-\mathrm{N}$, and $\mathrm{C}-\mathrm{H}$, respectively, can be inferred from bases of DNA. These results denote that the DNA was successfully modified on the surface of Au@Pt.

\section{Optimization of the Experimental Conditions}

This section investigated the influence of important factors, such as $\mathrm{pH}$ value, DNA concentration, and reaction time, to achieve the optimal experimental conditions for $\mathrm{CBZ}$ detection. The $\mathrm{pH}$ plays a crucial role in the preparation of the Au@Pt probe. A series of $\mathrm{pH}$ ranges $(4.0,5.0,6.0,7.0,8.0,9.0$, and 10.0) was set to estimate the optimal value for forming the Au@Pt probe. The catalytic efficiency of the Au@Pt probe was decreased with increasing the $\mathrm{pH}$ value to 8.0 (as depicted in Figure 3A). The DNA is easily degraded under acidic conditions (low $\mathrm{pH}$ value). The Au@Pt probe catalytic efficiency was increased because more catalytic active sites were exposed with a low concentration of DNA modified on the surface of Au@Pt nanomaterials. Thus, the optimal $\mathrm{pH}$ value was set at 8.0 for this assay. The sensitivity of the competitive assay based on Au@Pt-dsDNA- $\mathrm{Fe}_{3} \mathrm{O}_{4}$ biosensor depends on the DNA concentrations modified on the surface of Au@Pt. Then, the DNA concentration was carefully optimized as well. Different DNA concentrations $(0,0.1,0.5,1.0,1.5$, and $2.0 \mu \mathrm{M}$ ) were designed to prepare the Au@Pt probe. Like the influence of $\mathrm{pH}$, the catalytic efficiency of the Au@Pt probe was reduced with a high concentration of DNA, as can be displayed from Figure 3B, reaching maximum absorbance at $1.0 \mu \mathrm{M}$. Notably, this evidence demonstrated that the optimal concentration of DNA was $1.0 \mu \mathrm{M}$ in this assay. It is essential to optimize the reaction time between CBZ and Au@Pt probe to detect CBZ rapidly. In turn, a set of reaction times $(5,10$, $15,20,25$, and $30 \mathrm{~min}$ ) were designed to achieve the optimal reaction time. As time increased, the catalytic efficiency of the $\mathrm{Au} @ \mathrm{Pt}$ probe was improved, reaching the maximum absorbance at $20 \mathrm{~min}$ (as shown in Figure 3C). Thus, $20 \mathrm{~min}$ was identified as the optimized reaction time for the following experiments.

\section{Qualitative Analysis}

The $\mathrm{CBZ}$ and the $\mathrm{Fe}_{3} \mathrm{O}_{4}$ probe competitively react with DNAmodified nanomaterials Au@Pt to form Au@Pt-ssDNA-CBZ biosensor and Au@Pt-dsDNA- $\mathrm{Fe}_{3} \mathrm{O}_{4}$ biosensor, respectively. The Au@Pt-ssDNA-CBZ biosensor solution color dramatically changed from light blue to dark blue with Au@Pt-ssDNA-CBZ biosensor to catalyze TMB when the concentration of CBZ increased from 0 to $100 \mathrm{ng} / \mathrm{ml}$ (as shown in Figure 4A). The catalytic efficiency of the Au@Pt-ssDNA-CBZ biosensor was improved by increasing the CBZ concentration. The Au@PtssDNA-CBZ biosensor catalytic efficiency was increased because more catalytic active sites were exposed in the presence of $\mathrm{CBZ}$, which was bonded to the DNA on the surface of 
$\mathbf{A}$

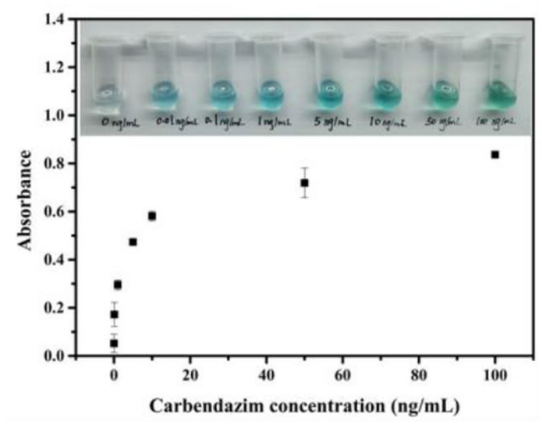

B

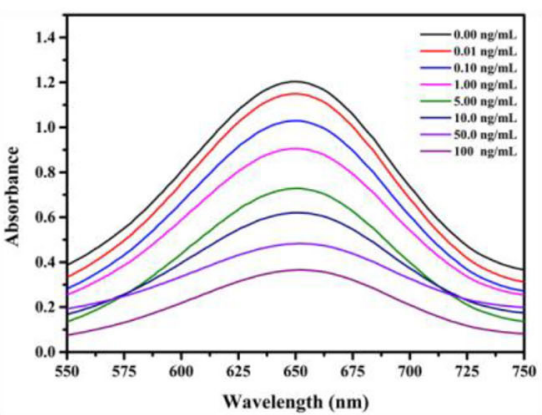

C

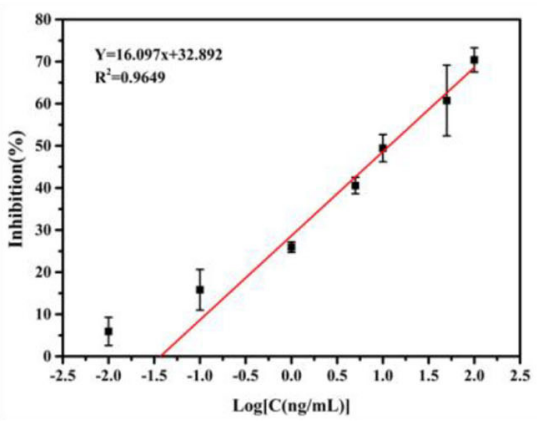

FIGURE 4 | Construction of the calibration curve. (A) UV-vis spectra absorbance for various concentrations of carbendazim (CBZ); (B) the absorbance scan with CBZ concentration (0.00-100 ng/ml); and (C) calibration curve of a competitive assay based on Au@Pt-dsDNA- $\mathrm{Fe}_{3} \mathrm{O}_{4}$ biosensor $(n=3)$.

TABLE 1 | Calibration curve of carbendazim (CBZ) in field incurred samples $(n=3)$.

\begin{tabular}{lccccc}
\hline Samples & $\begin{array}{c}\text { Spiked concentration } \\
\text { (ng/mg) }\end{array}$ & $\begin{array}{c}\text { Recovery } \\
\text { (\%) }\end{array}$ & RSD (\%) & $\begin{array}{c}\mathbf{I C}_{\mathbf{5 0}} \\
\text { (ng/mg) }\end{array}$ & $\begin{array}{c}\text { LOD } \\
\text { (ng/mg) }\end{array}$ \\
\hline Leek & 10 & $71.88 \pm 0.04$ & 10.91 & 7.56 & 0.044 \\
& 50 & $96.40 \pm 0.01$ & 3.93 & & \\
Rice & 100 & $110.11 \pm 0.02$ & 6.76 & 6.08 & 0.041 \\
& 10 & $91.62 \pm 0.03$ & 6.52 & & 0.9453 \\
& 50 & $89.86 \pm 0.01$ & 4.21 & & \\
& 100 & $107.45 \pm 0.01$ & 3.16 & & \\
\end{tabular}

$C_{50}$ : Represents the concentration at which a substance exerts half of its maximal inhibitory effect.

Au@Pt nanomaterials. Hence, the designed Au@Pt-ssDNA-CBZ biosensor could use as a qualitative analysis biosensor for on-site pesticide monitoring in the agro-products.

\section{Quantitative Analysis (Calibration Curves)}

The calibration curve was established based on Au@PtdsDNA- $\mathrm{Fe}_{3} \mathrm{O}_{4}$ biosensor catalysis in the competitive assay. The absorbance intensity decreased as the CBZ concentration increased in this study, as depicted in Figure 4B. It displayed a maximum absorbance at $650 \mathrm{~nm}$. The calibration curve of the competitive assay based on $\mathrm{Au} @ \mathrm{Pt}$-dsDNA- $\mathrm{Fe}_{3} \mathrm{O}_{4}$ biosensor for detection of CBZ pesticide was established under the optimal condition (Figure 4C). The calibration regression equation of curve $(Y=16.097 \mathrm{x}+32.892)$ was achieved with a wide linear range. $\mathrm{Y}$ represented the inhibition rate (\%) and the logarithmic ( $\mathrm{Log}$ ) concentration of $\mathrm{CBZ}$ as the $\mathrm{X}$ abscissa axis. A lowdetection limit $(0.038 \mathrm{ng} / \mathrm{mg})$ was acquired with a good linear relationship $\left(R^{2}=0.9649\right)$. The RSDs ranged from 1.56 to $10.22 \%$. The LOD of this assay was lower than the maximum residue limit (MRL) of CBZ enacted by China (GB 2763-2021) in various agro-products.

\section{Assay Evaluation}

The method was validated in terms of accuracy, precision, and LODs. The accuracy (recoveries of the proposed assay), precision (RSDs of the proposed assay), LODs, and correlation coefficients ( $R^{2}$ of regression equation) were used to evaluate the reliability, applicability, and sensitivity of the assay. To determine the validation parameters, three concentrations (10, 50 , and $100 \mathrm{ng} / \mathrm{mg}$ ) of CBZ standard solutions were chosen. For leek samples, the average recoveries ranged from 71.88 to $110.11 \%$ with RSDs (3.93-10.91\%), and a low LOD (0.044 $\mathrm{ng} / \mathrm{mg})$ and $\mathrm{IC}_{50}(7.56 \mathrm{ng} / \mathrm{mg})$ were acquired in the competitive assay. Like leeks', average recoveries of rice, RSDs, LOD, and IC $_{50}$ were $89.86-107.45 \%, 4.21-6.52 \%, 0.041 \mathrm{ng} / \mathrm{mg}$ and 6.08 $\mathrm{ng} / \mathrm{mg}$, respectively (Table 1 ). The regression equations were $Y=17.905 x+34.267$ and $Y=18.718 x+36.535$ for leeks and rice, respectively. Hence, good correlations $\left(R^{2} 0.9613\right.$ for leeks and 0.9453 for rice) were gained using the competitive assay (Table 1, Supplementary Figure 3). Therefore, the Au@PtdsDNA-Fe $\mathrm{O}_{4}$ biosensor of this competitive assay holds the potential as a sensitive and reliable assay for residual trace detection of pesticides.

\section{Specificity}

Specificity, recognizing the target molecule, is essential in the performance evaluation (33). The accuracy of the assay method is mainly based on the specificity of the CBZ aptamer (2). Several commonly used fungicides and insecticides $(100 \mathrm{ng} / \mathrm{ml}$ solution of imidacloprid, procymidone, chlorpyrifos, and acetamiprid) 


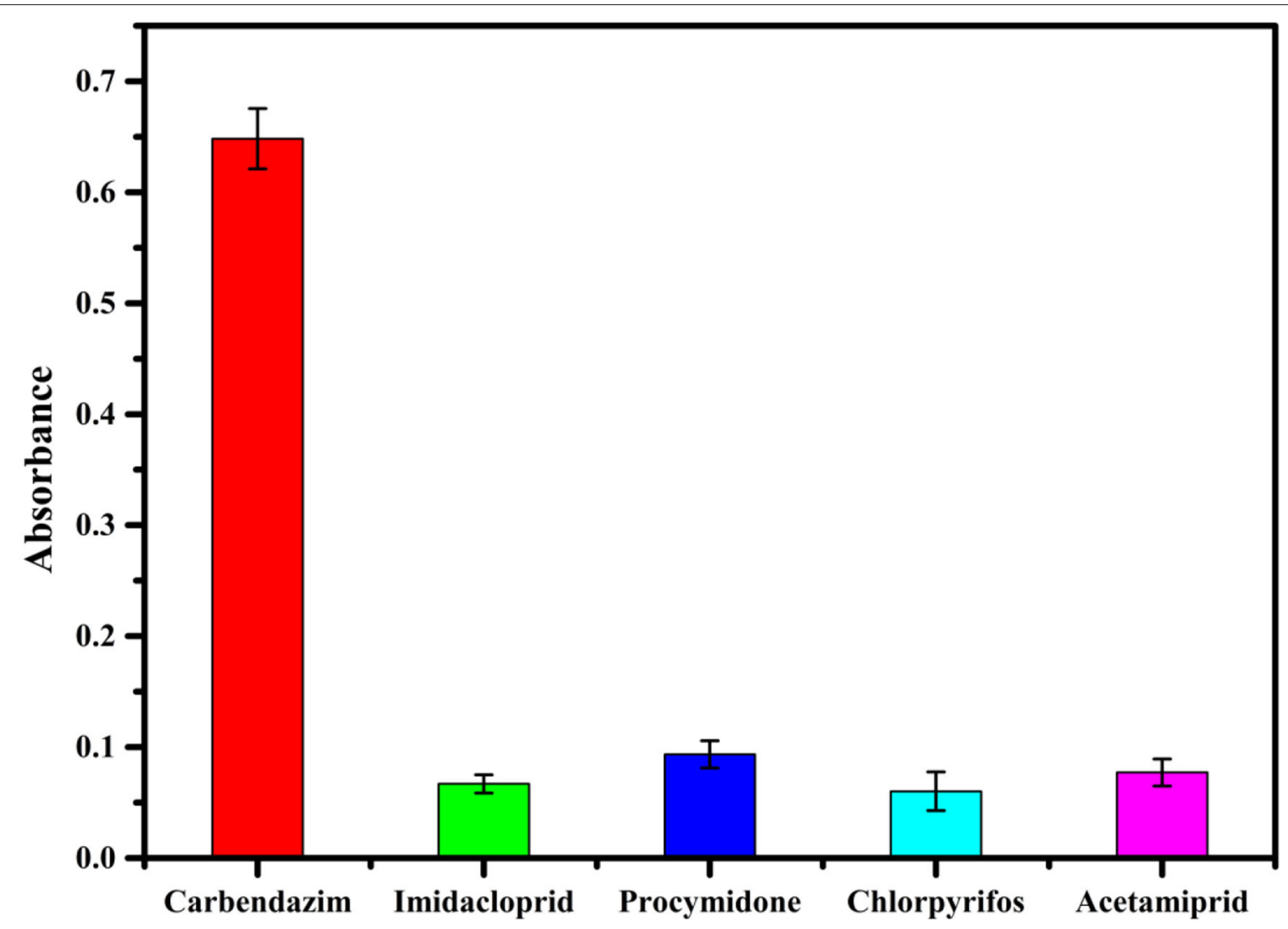

FIGURE 5 | Specificity between CBZ and other unrelated pesticides.

were investigated to evaluate the specificity of the proposed competitive assay for detection of CBZ. As can be inferred from Figure 5, the absorbance of the Au@Pt-ssDNA-CBZ biosensor increased only in the presence of CBZ. In contrast, other pesticides caused minor changes in absorbance. Hence, imidacloprid, procymidone, chlorpyrifos, and acetamiprid have a negligible effect on the proposed competitive assay in the presence of CBZ.

\section{Confirmation Analysis}

To further confirm the proposed accuracy of the assay, the blank leeks and rice samples were randomly selected to establish the correlation between the competitive assay and LC-MS/MS method (the parameters of LC-MS/MS shown in Supplementary Table 2). Five concentrations (5, 10, 20, 50, and $100 \mathrm{ng} / \mathrm{mg})$ of CBZ were spiked to blank leek $(n=24)$ and rice $(n$ $=24$ ) samples with vigorous shaking. Half of the samples were analyzed by the proposed competitive assay based on Au@PtdsDNA- $\mathrm{Fe}_{3} \mathrm{O}_{4}$ biosensor, and the rest were quantified with LCMS/MS. The correlation coefficients were achieved to assess the association between both methods. The correlation coefficients were 0.9339 and 0.9321 for leek and rice, respectively (Figure 6, Supplementary Table 3). These findings denote that competitive assay has good reliability to satisfy the requirements for pesticide detection in agro-products.

\section{DISCUSSION}

This study proposed dual-mode Au@Pt-DNA biosensors (Au@Pt-ssDNA-CBZ biosensor and Au@Pt-dsDNA-Fe ${ }^{3} \mathrm{O}^{4}$ biosensor) to analyze CBZ residues agricultural products.

The construction of the Au@Pt probe is the main key factor for Au@Pt-DNA biosensors. The EDS, UV-vis and FT-IR techniques were used to characterize the Au@Pt probe. Compared with Au@Pt nanoparticles (as depicted in Supplementary Figure 1B), the EDS of the Au@Pt probe has shown a $P$ element signal (Figure 2B). It has been deduced that the $P$ element is derived from DNA. A prominent characteristic absorbance peak (near $260 \mathrm{~nm}$ ) was noticed in UVvis spectroscopy of the Au@Pt probe (Figure 2C). As reported, the maximum absorption peak of DNA occurs at $260 \mathrm{~nm}$ (23). The characteristic peaks of $1,351,1,251$, and $950 \mathrm{~cm}^{-1}$, corresponding to $\mathrm{C}=\mathrm{C}, \mathrm{C}-\mathrm{N}$, and $\mathrm{C}-\mathrm{H}$, were observed in the FTIR spectra of the Au@Pt probe, as shown in Figure 2D. These results denote that the Au@Pt probe was successfully prepared.

The $\mathrm{pH}$ value, DNA concentration, and reaction time were investigated for establishing the assay based on Au@Pt-DNA biosensors to detect CBZ. The DNA is easily degraded under acidic conditions. The catalytic efficiency of the Au@Pt probe achieved the best results when the $\mathrm{pH}$ value reached 8.0 (Figure 3A). Similarly, the concentration of DNA at $1.0 \mu \mathrm{M}$, the catalytic efficiency of the Au@Pt probe reached maximum 

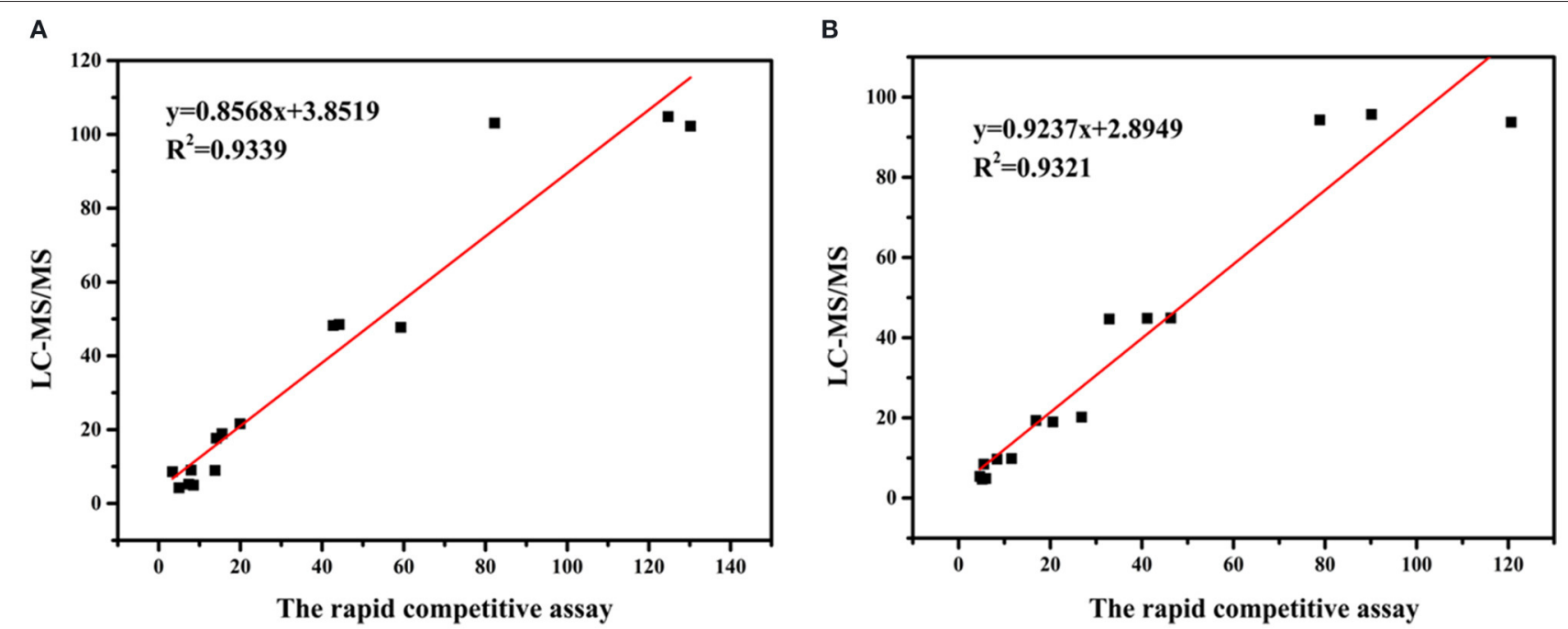

FIGURE 6 | Correlation between the concentrations of CBZ measured by the proposed competitive assay based on Au@Pt-dsDNA-Fe $\mathrm{O}_{4}$ mediated biosensor and LC-MS/MS in (A) leeks and $\mathbf{( B )}$ rice.

absorbance (Figure 3B). The Au@Pt probe with low DNA concentration achieves poor sensitivity. However, the higher DNA concentration inhibits the Au@Pt probe catalysis efficiency because too much DNA concentration might be covering the catalytic site on the Au@Pt nanozyme.

The Au@Pt-ssDNA-CBZ biosensor solution color dramatically changed from light blue to dark blue with Au@Pt-ssDNA-CBZ biosensor to catalyze TMB when the concentration of CBZ increased from 0 to $100 \mathrm{ng} / \mathrm{ml}$ (as shown in Figure 4A). The catalytic efficiency of the Au@Pt-ssDNA-CBZ biosensor improved by increasing the CBZ concentration because more catalytic active sites of Au@Pt were exposed in the presence of CBZ that was bonded to the DNA on the surface of Au@Pt nanomaterials. Hence, the designed Au@Pt-ssDNACBZ biosensor could use as a qualitative analysis biosensor for on-site pesticide monitoring in agro-products through naked-eye visualization.

In addition, the $\mathrm{Au} @ \mathrm{Pt}-\mathrm{dsDNA}-\mathrm{Fe}_{3} \mathrm{O}_{4}$ biosensor was regarded as quantitate analysis biosensor to establish a sensitive and reliable assay for residual trace detection of pesticides. The regression equation of calibration curve' $(Y=16.097 \mathrm{x}+32.892$, $\left.R^{2}=0.9649\right)$ was achieved. This assay acquired a low LOD $(0.038$ $\mathrm{ng} / \mathrm{mg}$ ) with RSDs ranged from 1.56 to $10.22 \%$ (Figure 4C). The leeks and rice samples were selected to monitor the residual levels of CBZ using the proposed assay. As shown in Table 1, the mean recoveries (leeks: $71.88-110.11 \%$, rice: $89.86-107.45 \%$ ) meet the EU guidance document for pesticide residue testing (SANTE/11813/2017). This assay acquired a low LOD (0.038 $\mathrm{ng} / \mathrm{mg}$ ) with RSDs ranging from 1.56 to $10.22 \%$. Therefore, the Au@Pt-dsDNA- $\mathrm{Fe}_{3} \mathrm{O}_{4}$ biosensor of this competitive assay holds the potential as a sensitive and reliable assay for residual trace detection of pesticides. Compared with other assays based on nanomaterials, such as $\mathrm{Au} / \mathrm{Fe}_{3} \mathrm{O}_{4}$ (6), UCNPs- $\mathrm{MnO}_{2}$ (34), AuNPs (35, 36), $\mathrm{Nd}_{2} \mathrm{O}_{3}$ (37), and $\mathrm{MoS}_{2}$ /MWCNTs (38) for CBZ detection is compiled in Table 2. As shown, this proposed
TABLE 2 | Various assays for detection of CBZ based on nanomaterials.

\begin{tabular}{lccl}
\hline Nanomaterials & Recovery (\%) & LOD & Reference \\
\hline $\mathrm{Au} @ \mathrm{Pt}$ & $71.88-110.11 \%$ & $0.037 \mathrm{ng} / \mathrm{mg}$ & This work \\
$\mathrm{Au} / \mathrm{Fe}_{3} \mathrm{O}_{4}$ & $102.4-115.0 \%$ & $0.44 \mathrm{ng} / \mathrm{ml}$ & $(6)$ \\
$\mathrm{UCNPS}-\mathrm{MnO}_{2}$ & $85.58-109.40 \%$ & $0.05 \mathrm{ng} / \mathrm{ml}$ & $(34)$ \\
$\mathrm{AuNPs}$ & $94.9-104.8 \%$ & $2.2 \mathrm{nM}$ & $(35)$ \\
$\mathrm{AuNPs}$ & $96.3-111.2 \%$ & $2.33 \mathrm{nM}$ & $(36)$ \\
$\mathrm{Nd}_{2} \mathrm{O}_{3}$ & - & $0.027 \mathrm{mM}$ & $(37)$ \\
$\mathrm{MoS}_{2} / \mathrm{MWCNTS}$ & $89.18-105.56 \%$ & $7.4 \mathrm{nM}$ & $(38)$ \\
\hline
\end{tabular}

competitive assay based on dual-mode Au@Pt-DNA biosensors acquires much lower LOD than other nanomaterials. Besides, the LOD of this assay is much lower than the MRL of CBZ set by China in various agro-products.

\section{CONCLUSIONS AND FUTURE PERSPECTIVES}

A competitive assay based on dual-mode Au@Pt-DNA biosensors combined aptamer (DNA) specific recognition property, bimetallic nanomaterials Au@Pt catalysis, and $\mathrm{Fe}_{3} \mathrm{O}_{4}$ magnetic separation was proposed to trace the $\mathrm{CBZ}$ residue. The qualitative Au@Pt-ssDNA-CBZ biosensor with aptamer (DNA) specific recognition property monitors pesticides through light blue to dark blue visualization and quantitative Au@PtdsDNA- $\mathrm{Fe}_{3} \mathrm{O}_{4}$ biosensor with bimetallic nanomaterials Au@Pt catalysis and $\mathrm{Fe}_{3} \mathrm{O}_{4}$ magnetic separation detect $\mathrm{CBZ}$ residue, respectively. Overall, this proposed competitive assay holds the potential as a sensitive and reliable assay for residual trace detection of pesticides and can be used for rapid on-site pesticide 
monitoring, reducing false-negative results, and improving screening efficiency and sensitivity.

\section{DATA AVAILABILITY STATEMENT}

The original contributions presented in the study are included in the article/Supplementary Material, further inquiries can be directed to the corresponding authors.

\section{AUTHOR CONTRIBUTIONS}

GC and DX investigated, designed, and wrote the original draft. $\mathrm{RZ}, \mathrm{GL}$, and $\mathrm{XH}$ investigated and supervised the article. $\mathrm{KZ}$, $\mathrm{XX}, \mathrm{LL}$, and $\mathrm{YZ}$ visualized and investigated. MJ, JW, and AA were involved in investigation and writing (review and editing) the manuscript. All the authors contributed to the article and approved the submitted version.

\section{REFERENCES}

1. Chuang S, Yang H, Wang X, Xue C, Jiang J, Hong Q. Potential effects of Rhodococcus qingshengii strain djl-6 on the bioremediation of carbendazimcontaminated soil and the assembly of its microbiome. J Hazard Mater. (2021) 414:125496. doi: 10.1016/j.jhazmat.2021.125496

2. Fu R, Zhou J, Liu Y, Wang Y, Liu H, Pang J, et al. Portable and quantitative detection of carbendazim based on the readout of a thermometer. Food Chem. (2021) 351:129292. doi: 10.1016/j.foodchem.2021.129292

3. Liu Z, Chen Y, Han J, Chen D, Yang G, Lan T, et al. Determination, dissipation dynamics, terminal residues and dietary risk assessment of thiophanatemethyl and its metabolite carbendazim in cowpeas collected from different locations in China under field conditions. J Sci Food Agric. (2021) 101:5498507. doi: 10.1002/jsfa.11198

4. Li P, Sun P, Dong X, Li B. Residue analysis and kinetics modeling of thiophanate-methyl, carbendazim, tebuconazole, and pyraclostrobin in apple tree bark using QuEChERS/HPLC-VWD. Biomed Chromatogr. (2020) 34:e4851. doi: 10.1002/bmc.4851

5. Chu Y, Tong Z, Dong X, Sun M, Gao $T$, Duan J, et al. Simultaneous determination of 98 pesticide residues in strawberries using UPLC-MS/MS and GC-MS/MS. Microchem J. (2020) 156:104975. doi: 10.1016/j.microc.2020.104975

6. Li Q, Dou X, Zhao X, Zhang L, Luo J. Xing, X, et al. A gold $/ \mathrm{Fe}_{3} \mathrm{O}_{4}$ nanocomposite for use in a surface plasmon resonance immunosensor for carbendazim. Microchim Acta. (2019) 186:313. doi: 10.1007/s00604-019-3402-0

7. Koukouvinos G, Karachaliou CE, Raptis I, Petrou P, Livaniou E, Kakabakos S. Fast and sensitive determination of the fungicide carbendazim in fruit juices with an immunosensor based on white light reflectance spectroscopy. Biosensors. (2021) 11:153. doi: 10.3390/bios11050153

8. Qiao Q, Guo X, Wen F, Chen L, Xu Q, Zheng N, et al. Aptamer-based fluorescence quenching approach for detection of aflatoxin M1 in milk. Front Chem. (2021) 9:653869. doi: 10.3389/fchem.2021.653869

9. Zhao X, Zhang X, Qin M, Song Y, Zhang J, Xia X, et al. Determination of carbendazim by aptamer-based fluorescence resonance energy transfer (FRET). Anal Lett. (2020) 54:2198-210. doi: 10.1080/00032719.2020.1849250

10. Zikos C, Evangelou A, Karachaliou CE, Gourma G, Blouchos P, Moschopoulou G, et al. Commercially available chemicals as immunizing haptens for the development of a polyclonal antibody recognizing carbendazim and other benzimidazole-type fungicides. Chemosphere. (2015) 119:16-20. doi: 10.1016/j.chemosphere.2014.03.049

11. Yan $\mathrm{H}$, Liu $\mathrm{L}, \mathrm{Xu} \mathrm{N}$, Kuang $\mathrm{H}, \mathrm{Xu}$ C. Development of an immunoassay for carbendazim based on a class-selective monoclonal antibody. Food Agric Immunol. (2015) 26:659-70. doi: 10.1080/09540105.2015.1007446

\section{FUNDING}

This study was financially supported by Central Publicinterest Scientific Institution Basal Research Fund, Chinese Academy of Agricultural Sciences (IVF-BRF2021020), the Agricultural Science and Technology Innovation Program of CAAS (CAAS-ZDRW202011 and CAAS-TCX2019025-5), the China Agriculture Research System of MOF and MARA (CARS23-E03), and the National Key Research Development Program of China (2020YFD1000300).

\section{SUPPLEMENTARY MATERIAL}

The Supplementary Material for this article can be found online at: https://www.frontiersin.org/articles/10.3389/fnut.2022. 820150/full\#supplementary-material

12. Zhou W, Huang PJ, Ding J, Liu J. Aptamer-based biosensors for biomedical diagnostics. Analyst. (2014) 139:2627-40. doi: 10.1039/c4an00132j

13. Fan K, Yang R, Zhao Y, Zang C, Miao X, Qu B, et al. A fluorescent aptasensor for sensitive detection of isocarbophos based on AT-rich three-way junctions DNA templated copper nanoparticles and $\mathrm{Fe}_{3} \mathrm{O}_{4} @$ GO. Sens Actuators B. (2020) 321:128515. doi: 10.1016/j.snb.2020.128515

14. McConnell EM, Nguyen J, Li Y. Aptamer-based biosensors for environmental monitoring. Front Chem. (2020) 8:434. doi: 10.3389/fchem.2020.00434

15. Shi YQ Li WT, Feng XP, Lin L, Nie PC, Shi JY, et al. Sensing of mercury ions in Porphyra by Copper@Gold nanoclusters based ratiometric fluorescent aptasensor. Food Chem. (2021) 344:10. doi: 10.1016/j.foodchem.2020.128694

16. Zhang WW, Wang YL, Nan MN Li YC, Yun JM, Wang Y, et al. Novel colorimetric aptasensor based on unmodified gold nanoparticle and ssDNA for rapid and sensitive detection of T-2 toxin. Food Chem. (2021) 348:8. doi: 10.1016/j.foodchem.2021.129128

17. Nan MN Bi Y, Xue HL, Long HT, Xue SL, Pu LM, et al. Modification performance and electrochemical characteristics of different groups of modified aptamers applied for label-free electrochemical impedimetric sensors. Food Chem. (2021) 337:6. doi: 10.1016/j.foodchem.2020.127761

18. Wei H, Wang EK. Nanomaterials with enzyme-like characteristics (nanozymes): next-generation artificial enzymes. Chem Soc Rev. (2013) 42:6060-93. doi: 10.1039/c3cs35486e

19. Weerathunge P, Behera BK, Zihara S, Singh M, Prasad SN, Hashmi S, et al. Dynamic interactions between peroxidase-mimic silver nanozymes and chlorpyrifos-specific aptamers enable highly-specific pesticide sensing in river water. Anal Chim Acta. (2019) 1083:157-65. doi: 10.1016/j.aca.2019.07.066

20. Wang Q, Wei H, Zhang Z, Wang E, Dong S. Nanozyme: An emerging alternative to natural enzyme for biosensing and immunoassay. $\operatorname{Tr} A C$, Trends Anal Chem. (2018) 105:218-24. doi: 10.1016/j.trac.2018.05.012

21. Sim S, Beierle A, Mantos P, McCrory S, Prasankumar RP, Chowdhury S. Ultrafast relaxation dynamics in bimetallic plasmonic catalysts. Nanoscale. (2020) 12:10284-91. doi: 10.1039/D0NR00831A

22. Lu C, Tang L, Gao F, Li Y, Liu J, Zheng J. DNA-encoded bimetallic Au-Pt dumbbell nanozyme for high-performance detection and eradication of Escherichia coli O157:H7. Biosens Bioelectron. (2021) 187:113327. doi: 10.1016/j.bios.2021.113327

23. Chen G, Liu G, Jia H, Cui X, Wang Y, Li D, et al. A sensitive biobarcode immunoassay based on bimetallic Au@Pt nanozyme for detection of organophosphate pesticides in various agro-products. Food Chem. (2021) 362:130118. doi: 10.1016/j.foodchem.2021.130118

24. Tian J, Liang Z, Hu O, He Q, Sun D, Chen Z. An electrochemical dual-aptamer biosensor based on metal-organic frameworks MIL-53 decorated with Au@Pt nanoparticles and enzymes for detection of COVID-19 nucleocapsid protein. Electrochim Acta. (2021) 387:138553. doi: 10.1016/j.electacta.2021.138553 
25. Wei SS, Xiao HL, Gu M, Chen ZC, Cao LL. Ultrasensitive label-free electrochemical immunosensor based on core-shell Au@PtNPs functionalized rGO-TEPA/PB nanocomposite for HBsAg detection. J Electroanal Chem. (2021) 890:9. doi: 10.1016/j.jelechem.2021.115216

26. Ma JL, Yin BC, Wu X, Ye BC. Copper-mediated dna-scaffolded silver nanocluster switch for detection of pyrophosphate and alkaline phosphatase. Anal Chem. (2016) 88:9219-25. doi: 10.1021/acs.analchem.6b02465

27. Jin X, Chen L, Zhang YT, Wang XL, Zhou ND, A. lateral flow strip for on-site detection of tobramycin based on dual-functional platinum-decorated gold nanoparticles. Analyst. (2021) 146:3608-16. doi: 10.1039/D1AN00403D

28. Chen G, Jin M, Ma J, Yan M, Cui X, Wang Y, et al. Competitive biobarcode immunoassay for highly sensitive detection of parathion based on bimetallic nanozyme catalysis. J Agric Food Chem. (2021) 68:6608. doi: 10.1021/acs.jafc.9b06125

29. Sajwan RK, Lakshmi G, Solanki PR. Fluorescence tuning behavior of carbon quantum dots with gold nanoparticles via novel intercalation effect of aldicarb. Food Chem. (2021) 340:9. doi: 10.1016/j.foodchem.2020.127835

30. Wu X, Song Y, Yan X, Zhu C, Ma Y, Du D, et al. Carbon quantum dots as fluorescence resonance energy transfer sensors for organophosphate pesticides determination. Biosens Bioelectron. (2017) 94:292-7. doi: 10.1016/j.bios.2017.03.010

31. Eissa S, Zourob M. Selection and characterization of DNA aptamers for electrochemical biosensing of carbendazim. Anal Chem. (2017) 89:313845. doi: 10.1021/acs.analchem.6b04914

32. Anastassiades M, Lehotay SJ, Stajnbaher D, Schenck FJ. Fast and easy multiresidue method employing acetonitrile extraction/partitioning and "dispersive solid-phase extraction" for the determination of pesticide residues in produce. J AOAC Int. (2003) 86:412-31. doi: 10.1093/jaoac/86.2.412

33. Ouyang Q, Wang L, Ahmad W, Rong Y, Li H, Hu Y, et al. A highly sensitive detection of carbendazim pesticide in food based on the upconversion$\mathrm{MnO}_{2}$ luminescent resonance energy transfer biosensor. Food Chem. (2021) 349:129157. doi: 10.1016/j.foodchem.2021.129157

34. Zhang XL, Wu D, Zhou XX Yu YX, Liu JC, Hu N, et al. Recent progress in the construction of nanozyme-based biosensors and their applications to food safety assay. TrAC, Trends Anal Chem. (2019) 121:22. doi: 10.1016/j.trac.2019.115668
35. Wang S, Su L, Wang L, Zhang D, Shen G, Ma Y. Colorimetric determination of carbendazim based on the specific recognition of aptamer and the poly-diallyldimethylammonium chloride aggregation of gold nanoparticles. Spectrochim Acta, Part A. (2020) 228:117809. doi: 10.1016/j.saa.2019.117809

36. Zhou Y, Li Y, Han P, Dang Y, Zhu M, Li Q, et al. A novel low-dimensional heteroatom doped $\mathrm{Nd}_{2} \mathrm{O}_{3}$ nanostructure for enhanced electrochemical sensing of carbendazim. New J Chem. (2019) 43:1400919. doi: 10.1039/C9NJ02778E

37. Zhu X, Liu P, Ge Y, Wu R, Xue T, Sheng Y, et al. $\mathrm{MoS}_{2} / \mathrm{MWCNTs}$ porous nanohybrid network with oxidase-like characteristic as electrochemical nanozyme sensor coupled with machine learning for intelligent analysis of carbendazim. J Electroanal Chem. (2020) 862:113940. doi: 10.1016/j.jelechem.2020.113940

38. Su L, Wang S, Wang L, Yan Z, Yi H, Zhang D, et al. Fluorescent aptasensor for carbendazim detection in aqueous samples based on gold nanoparticles quenching Rhodamine B. Spectrochim Acta, Part A. (2020) 225:117511. doi: 10.1016/j.saa.2019.117511

Conflict of Interest: The authors declare that the research was conducted in the absence of any commercial or financial relationships that could be construed as a potential conflict of interest.

Publisher's Note: All claims expressed in this article are solely those of the authors and do not necessarily represent those of their affiliated organizations, or those of the publisher, the editors and the reviewers. Any product that may be evaluated in this article, or claim that may be made by its manufacturer, is not guaranteed or endorsed by the publisher.

Copyright (C) 2022 Chen, Zhai, Liu, Huang, Zhang, Xu, Li, Zhang, Wang, Jin, Xu and Abd El-Aty. This is an open-access article distributed under the terms of the Creative Commons Attribution License (CC BY). The use, distribution or reproduction in other forums is permitted, provided the original author(s) and the copyright owner(s) are credited and that the original publication in this journal is cited, in accordance with accepted academic practice. No use, distribution or reproduction is permitted which does not comply with these terms. 